\title{
Synthesis, In-vitro Antioxidant, Anti-diabetic Evaluation and Docking Studies of Newly Synthesized Benzoxazole Derivatives
}

\author{
Manuel Rodrigues ${ }^{1}$, Basavaraju Bennehalli' ${ }^{1, *}$, \\ Vagdevi Hosadu Manjappaiah ${ }^{2}$ and Shruthi Anantha ${ }^{3}$ \\ ${ }^{1}$ Department of Chemistry, Alva's Institute of Engineering and Technology, Karnataka 574225, India \\ ${ }^{2}$ Department of Chemistry, Sahyadri Science College, Karnataka 577203, India \\ ${ }^{3}$ Department of Chemistry, Alva's College, Karnataka 574227, India
}

('Corresponding author's e-mail: basavaraju@aiet.org.in)

Received: 16 March 2021, Revised: 30 May 2021, Accepted: 16 June 2021

\begin{abstract}
In the present study, a set of different benzoxazole derivatives has been synthesized from ethyl acetoacetate, ethoxymethylene malononitrile, $\mathrm{NaNO}_{2}$, and organic acids. Analytical instruments like proton NMR $\left({ }^{1} \mathrm{H}\right)$, carbon NMR $\left({ }^{13} \mathrm{C}\right)$, infrared spectroscopy (IR), and LC-MS mass spectrometry were used for structural characterization. Synthesized molecules were evaluated for In-vitro antioxidant property (DPPH assay, Total antioxidant \& reducing power method) and anti-diabetic property (alphaamylase \& alpha-glucosidase assay). In silico, studies against Human pancreatic alpha-amylase (PDB ID: 3BAW) have been carried out to get the binding approach of the ligand towards the protein. The results demonstrated that compounds namely $\mathbf{5 b}, \mathbf{6 b}, \mathbf{3 b}$ and $\mathbf{4 b}$ had potent antioxidant and anti-diabetic activity compared with ascorbic acid and acarbose.
\end{abstract}

Keywords: Benzoxazole, Ethoxymethylene malononitrile, Antioxidant, Anti-diabetic, Molecular docking

\section{Introduction}

Since diabetes has become one of the common problems of human beings, the researchers aimed to find novel methods to prevent and treat it. Although diabetes is caused by a corrupted immune system that destroys the pancreas cells to make proper insulin production, recent research shows that oxidative stress can also be the reason for less secretion of insulin [1]. Hence it is proven that diabetes can be managed with the use of the proper antioxidants.

Even though many molecules in heterocyclic compounds have antioxidant and antidiabetic activity, benzoxazole is one of the most potent moieties for biological evaluation, including both antioxidant [2] and anti-diabetic [3] assay. Literature survey also revealed that the substitution like sulfonamide group shows a variety of biological activities like anti-microbial, anti-inflammatory [4], antioxidant [5], antidiabetic [6], and anticancer [7] activities. The substitutions like chloro [2], nitro [2] also have good biological activities.

The considerable biological activities of benzoxazole [3,8,9] compounds in drug discovery and their importance in the medicinal field have stimulated the present investigation on the synthesis of derivatives of this ring system along with the substitutions like sulfonamide, nitro and chloro. Hence, it was planned to synthesize fused benzoxazole derivatives. However, the stability of the intermediate formed during the reactions are so high that the attempts to cyclize the molecule by cyclizing agents such as $\mathrm{NaOH}$, pyridine, $\mathrm{C}_{2} \mathrm{H}_{5} \mathrm{ONa}$ were not successful as depicted in Scheme 1. This is attributed to the fact that the molecules are small ligands and the literature survey has shown remarkable biological activity [10] for such molecules. The functionalities like sulfonamide [7], nitriles [11], tetrazole [12], halogens [13], nitro [14] groups as well as ester [15] derivatives of compounds have shown effective biological activities. Hence, synthesized molecules were exposed for in-vitro antioxidant and anti-diabetic investigation.

The synthesized molecules were screened for in silico anti-diabetic studies against Human pancreatic alpha-amylase (PDB ID: 3BAW). In silico, studies of synthesized molecules play a key role in predicting the best conformation considering the lowest binding energy and the number of hydrogen bonds. The results of In silico method were compared with the In-vitro studies. 


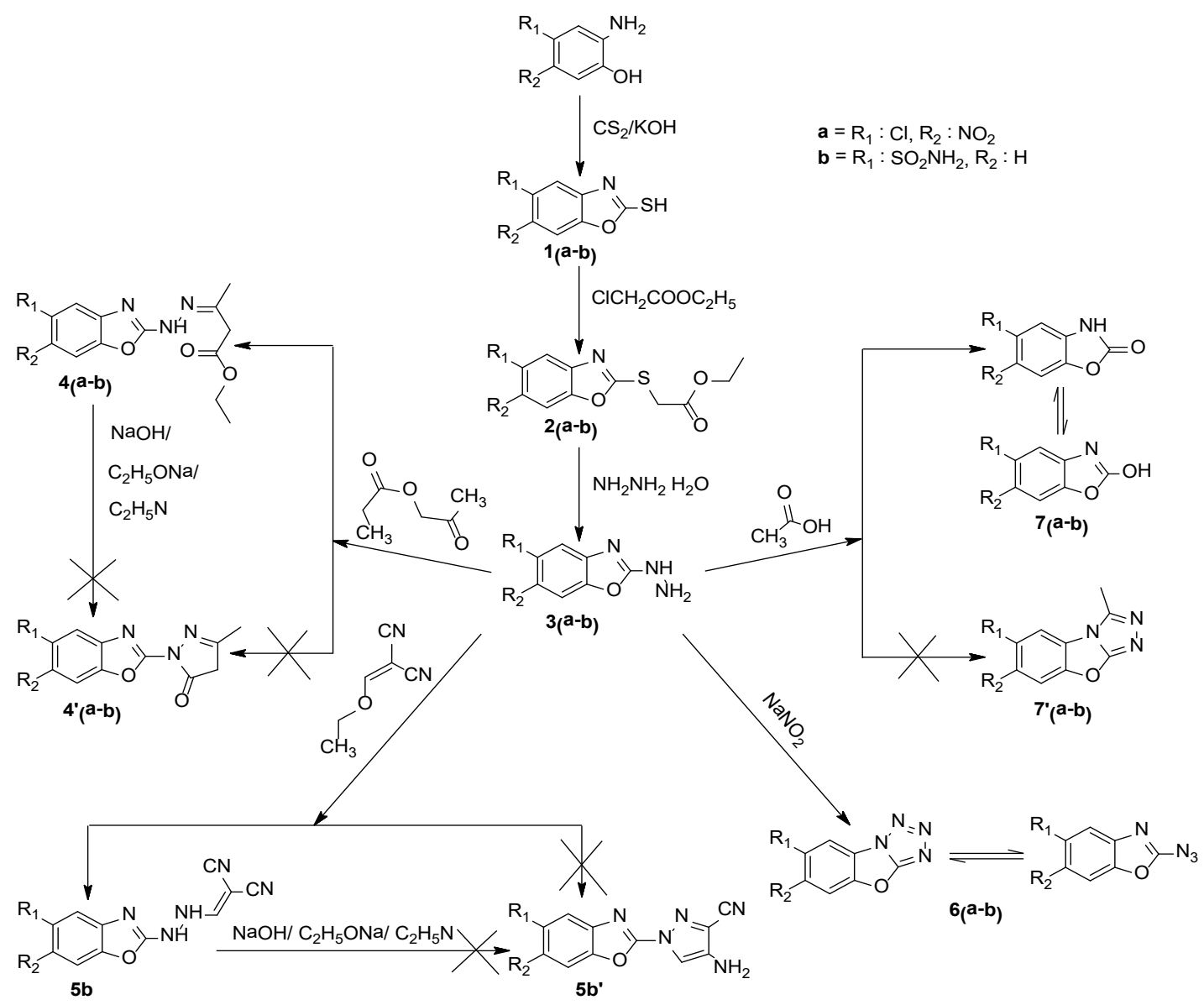

Scheme 1 Synthesis of 5-chloro-6-nitro and 5-sulfamoyl substituted benzoxazole derivatives.

\section{Materials and methods}

Chemistry

TMS was used as an internal standard for ${ }^{1} \mathrm{H}$ and ${ }^{13} \mathrm{C}$ NMR spectral analysis with $\delta$ values as ppm. NMR spectra was recorded on Bruker $400 \mathrm{MHz}$ spectrometer MIT, MAHE, Manipal, Karnataka, India and IISc, Bangalore, Karnataka, India. LC-MS was recorded on LCMS 2010A, SHIMADZU, JAPAN with $\mathrm{C} 18$ column and rate of flow $0.2 \mathrm{~mL} / \mathrm{min}$ using ESI (electron spray ionization) method. Bruker (ALPHA) Platinum ATR Fourier transformed infrared (FT-IR) spectrophotometer was used for recording IR spectra. 230e400 mesh-sized silica gel was used for column chromatography. Electrical melting point apparatus was used for determining melting point. VarioMICRO V1.7.0 (Elemental analysersysteme $\mathrm{GmbH}$ ) was used for Elemental analysis. For TLC analysis, silica gel $60 \mathrm{GF}_{254}$ (Merck) plates were used, and spots were analyzed by UV light of wavelength $254 \mathrm{~nm}$.

\section{5-chloro-6-nitro and 5-sulfamoyl substituted 1,3-benzoxazole-2-thiol (1a) and (1b)}

$\mathrm{KOH}(2.8 \mathrm{~g}, 0.05 \mathrm{~mol}) \& 60 \mathrm{~mL}$ of methanol was taken in a $100 \mathrm{~mL}$ round-bottomed flask. To this, $\mathrm{CS}_{2}(3 \mathrm{~mL}, 0.05 \mathrm{~mol})$ was added dropwise in ice-cold condition $\left(0-5{ }^{\circ} \mathrm{C}\right)$ with constant stirring for few minutes, followed by the addition of 4-chloro-5-nitro-2-aminophenol/opsamide (1.8 g, $0.01 \mathrm{~mol})$. The reaction mixture was refluxed for $3 \mathrm{~h} 30 \mathrm{~min}$ and $5 \mathrm{~h} 30 \mathrm{~min}$ respectively and poured to crushed ice, acidified with dilute acetic acid ( $\mathrm{pH}$ 6.0) with stirring which gives, 1a as orange-red solid (1.95 g, 84.56 \%), mp $189-191{ }^{\circ} \mathrm{C}$ and $\mathbf{1 b}$ as brownish solid $(1.82 \mathrm{~g}, 79.06 \%)$, mp $193-195{ }^{\circ} \mathrm{C}$, respectively. 5chloro-6-nitro-1,3-benzoxazole-2-thiol (1a): IR $\left(v_{\max } \mathrm{cm}^{-1}\right)$ : 3050, 1618, 1511, 661. ${ }^{1} \mathrm{H}$ NMR $(400 \mathrm{MHz}$, DMSO-d $\left.{ }_{6}\right): \delta_{\mathrm{H}} 8.14(1 \mathrm{H}, \mathrm{s}), 7.42(1 \mathrm{H}, \mathrm{s}) .{ }^{13} \mathrm{C}$ NMR (400 MHz, DMSO-d $\left.{ }_{6}\right): \delta_{\mathrm{c}} 115.1,118.4,124.9,140.5$, 145.7, 157.5 and 180.2 (C-SH). MS (LCMS): $m / z 231\left(\mathrm{M}^{+}\right), 233\left(\mathrm{M}^{+2}\right)$. Anal. calcd for $\mathrm{C}_{7} \mathrm{H}_{3} \mathrm{ClN}_{2} \mathrm{O}_{3} \mathrm{~S}$ (230.62): C, 36.45; H, 1.31; N, 12.15. Found: C, 36.34; H, 1.26; N, 12.08. 5-sulfamoyl-1,3-benzoxazole2-thiol (1b): IR $\left(v_{\max } \mathrm{cm}^{-1}\right): 3150,1331 .{ }^{1} \mathrm{H}$ NMR (400 MHz, DMSO-d 6 ): $\delta_{\mathrm{H}} 7.454(2 \mathrm{H}$, s, sulfonamide 
$\mathrm{NH}_{2}$, disappeared on $\mathrm{D}_{2} \mathrm{O}$ exchange), $7.611-7.616(1 \mathrm{H}, \mathrm{dd}, J 1.7544 \mathrm{~Hz}, J 0.4649 \mathrm{~Hz}), 7.653-7.675$ $(1 \mathrm{H}, \mathrm{d}, J 0.4282), 7.709-7.713(1 \mathrm{H}, \mathrm{d}, J 1.7846), 14.159\left(1 \mathrm{H} \mathrm{s}, \mathrm{SH}\right.$, disappeared on $\mathrm{D}_{2} \mathrm{O}$ exchange). ${ }^{13} \mathrm{C}$ NMR (400 MHz, DMSO-d $\left.{ }_{6}\right): \delta_{c} 108.4,110.7,122.2,132.0,141.7,150.3$ (C benzoxazole) and 181.5 (CSH). MS (LCMS): $m / z 230\left(\mathrm{M}^{+}\right)$. Anal. calcd for $\mathrm{C}_{7} \mathrm{H}_{6} \mathrm{~N}_{2} \mathrm{O}_{3} \mathrm{~S}_{2}(230.26)$ : C, 36.51; H, 2.63; N, 12.17 . Found: C, 36.42; H, 2.55; N, 12.08 . and (2b)

5-chloro-6-nitro and 5-sulfamoyl substituted ethyl [(1,3-benzoxazol-2-yl)sulfanyl]acetate (2a)

Marcapto of substituted benzoxazole $(2.3 \mathrm{~g}, 0.01 \mathrm{~mol})(1 \mathrm{a} / 1 \mathrm{~b})$ was taken in a $100 \mathrm{~mL}$ roundbottomed flask containing dry acetone $(40 \mathrm{~mL})$ and anhydrous potassium carbonate $(3 \mathrm{~g})$ followed by the addition of ethyl chloroacetate $(1.1 \mathrm{~mL} 0.01 \mathrm{~mol})$. It was refluxed for $30 \mathrm{~min}$ and poured to crushed ice with constant stirring, which gave, $\mathbf{2 a}$ as pale grey color solid $(3.0 \mathrm{~g}, 94.94 \%), \mathrm{mp} 110-112{ }^{\circ} \mathrm{C}$ and $\mathbf{2 b}$ as pale pink solid (3.1 g, 98.1 \%), mp 140 - $142{ }^{\circ} \mathrm{C}$, respectively. ethyl [(5-chloro-6-nitro-1,3benzoxazol-2-yl)sulfanyl]acetate (2a): IR $\left(v_{\max } \mathrm{cm}^{-1}\right): 817,1311,1484,1741 .{ }^{1} \mathrm{H} \mathrm{NMR}(500 \mathrm{MHz}$, $\left.\mathrm{CDCl}_{3}\right): \delta_{\mathrm{H}} 8.02(1 \mathrm{H}, \mathrm{s}), 7.70(1 \mathrm{H}, \mathrm{s}), 4.11\left(2 \mathrm{H}, \mathrm{s}, \mathrm{S}-\mathrm{CH}_{2}\right), 4.23-4.28\left(2 \mathrm{H}, \mathrm{q}, J 7.1352 \mathrm{~Hz}, \mathrm{CH}_{2}\right.$ ester $)$, $1.28-1.31\left(3 \mathrm{H}, \mathrm{t}, J 7.1269 \mathrm{~Hz},-\mathrm{CH}_{3}\right) .{ }^{13} \mathrm{C}$ NMR (400 MHz, DMSO-d 6$): \delta_{\mathrm{c}} 15.1\left(-\mathrm{CH}_{3}\right), 36.4\left(\mathrm{~S}_{-} \mathrm{CH}_{2}\right)$, $60.5\left(-\mathrm{OCH}_{2}-\right), 111.1,114.7,126.7,139.2,144.2,156.1,164.9$ and $172.8(\mathrm{C}=\mathrm{O})$. MS (LCMS): $\mathrm{m} / z 317$ $\left(\mathrm{M}^{+}\right), 319(\mathrm{M}+2)$. Anal. calcd for $\mathrm{C}_{11} \mathrm{H}_{9} \mathrm{ClN}_{2} \mathrm{O}_{5} \mathrm{~S}$ (316.71): C, 41.71; H, 2.86; N, 8.84. Found: C, 41.62; $\mathrm{H}, 2.78 ; \mathrm{N}, 8.72$. ethyl [(5-sulfamoyl-1,3-benzoxazol-2-yl)sulfanyl]acetate (2b): $\mathrm{IR}\left(v_{\max } \mathrm{cm}^{-1}\right): 1191$, 1327, 1732. ${ }^{1} \mathrm{H}$ NMR $\left(400 \mathrm{MHz}, \mathrm{DMSO}-\mathrm{d}_{6}\right): \delta_{\mathrm{H}} 8.01(1 \mathrm{H}, \mathrm{d}, J 1.2059), 7.843(1 \mathrm{H}, \mathrm{s}), 7.79(1 \mathrm{H}, \mathrm{d}, J$ 1.7694), 4.325 (2H, s, S-CH $)$, 4.148-4.201 (2H, q, J 7.0983 Hz, $\mathrm{CH}_{2}$ ester), $1.185-1.221$ (3H, t, J 7.0979 $\left.\mathrm{Hz}, \mathrm{CH}_{3}\right), 7.424\left(2 \mathrm{H}\right.$, s, sulfonamide $\mathrm{NH}_{2}$, disappeared on $\mathrm{D}_{2} \mathrm{O}$ exchange). ${ }^{13} \mathrm{C}$ NMR (400 MHz, DMSO$\left.\mathrm{d}_{6}\right): \delta_{\mathrm{c}} 14.2\left(\mathrm{CH}_{3}\right), 35.1\left(\mathrm{~S}_{-} \mathrm{CH}_{2}\right), 61.5\left(\mathrm{OCH}_{2}\right), 110.1,115.5,125.4,138.6,145.2,155.2,165.7$ and 170.7 $(\mathrm{C}=\mathrm{O})$. MS (LCMS): $m / z 316\left(\mathrm{M}^{+}\right)$. Anal. calcd for $\mathrm{C}_{11} \mathrm{H}_{12} \mathrm{~N}_{2} \mathrm{O}_{5} \mathrm{~S}_{2}(316.35)$ : C, 41.76; H, 3.82; $\mathrm{N}, 8.86$. Found: C, 41.67; H, 3.76; N, 8.79.

\section{5-chloro-6-nitro and 5-sulfamoyl substituted 2-hydrazinyl-1,3-benzoxazole (3a) and (3b)}

Ester derivatives of substituted benzoxazole $(3.16 \mathrm{~g}, 0.01 \mathrm{~mol})(2 \mathrm{a}) /(2 \mathrm{~b})$ was taken in a $250 \mathrm{~mL}$ round-bottomed flask containing methanol $(100 \mathrm{~mL})$ followed by the addition of hydrazine hydrate $(2.5$ $\mathrm{mL}, 0.05 \mathrm{~mol}$ ), which were refluxed for $30 \mathrm{~min}$ and stirred for $30 \mathrm{~min}$, respectively. Reaction mixture was poured on to crushed ice with constant stirring gives, $3 \mathbf{a}$ as brown solid $(1.95 \mathrm{~g}, 85.3 \%), \mathrm{mp} 250-252^{\circ} \mathrm{C}$ and $\mathbf{3 b}$ as purple-violet color solid $(1.96 \mathrm{~g}, 85.74 \%)$, mp $220-222{ }^{\circ} \mathrm{C}$, respectively. 2-hydrazinyl-5chloro-6-nitro-1,3-benzoxazole (3a): IR $\left(v_{\max } \mathrm{cm}^{-1}\right)$ : 622, 1565, 1641, 3250. ${ }^{1} \mathrm{H}$ NMR $(200 \mathrm{MHz}$, DMSO-d $\left.{ }_{6}\right): \delta_{\mathrm{H}} 8.23(1 \mathrm{H}, \mathrm{s}), 7.51(1 \mathrm{H}, \mathrm{s}), 9.73\left(1 \mathrm{H}, \mathrm{s}, \mathrm{NH}\right.$, disappeared on $\mathrm{D}_{2} \mathrm{O}$ exchange $), 4.82(2 \mathrm{H}, \mathrm{s}$, $\mathrm{NH}_{2}$, disappeared on $\mathrm{D}_{2} \mathrm{O}$ exchange). ${ }^{13} \mathrm{C}$ NMR (400 MHz, DMSO-d $\left.{ }_{6}\right): \delta_{\mathrm{c}} 110.2,118.6,130.8,142.5$, 148.2, 159.6 and $168.9(\mathrm{C}-\mathrm{NH})$. MS (LCMS): $m / z 229\left(\mathrm{M}^{+}\right), 231\left(\mathrm{M}^{+2}\right)$. Anal. calcd for $\mathrm{C}_{7} \mathrm{H}_{5} \mathrm{ClN}_{4} \mathrm{O}_{3}$ (228.59): C, 36.78; H, 2.20; N, 24.51. Found: C, 36.68; H, 2.14; N, 24.46. 2-hydrazinyl-5-sulfamoyl1,3-benzoxazole (3b): IR $\left(v_{\max } \mathrm{cm}^{-1}\right): 1308,3000,3400 .{ }^{1} \mathrm{H}$ NMR $\left(400 \mathrm{MHz}, \mathrm{DMSO}-\mathrm{d}_{6}\right): \delta_{\mathrm{H}} 7.646(1 \mathrm{H}$, d, $J 1.2935 \mathrm{~Hz}), 7.503(1 \mathrm{H}, \mathrm{s}), 7.4903(1 \mathrm{H}, \mathrm{d}, J 1.71162 \mathrm{~Hz}), 9.102\left(1 \mathrm{H}, \mathrm{s}, \mathrm{NH}\right.$, disappeared on $\mathrm{D}_{2} \mathrm{O}$ exchange), $4.615\left(2 \mathrm{H}, \mathrm{s}, \mathrm{NH}_{2}\right.$, disappeared on $\mathrm{D}_{2} \mathrm{O}$ exchange), $7.260\left(2 \mathrm{H}, \mathrm{s}, 2 \mathrm{H}\right.$, sulfonamide $\mathrm{NH}_{2}$, disappeared on $\mathrm{D}_{2} \mathrm{O}$ exchange). ${ }^{13} \mathrm{C}$ NMR (400 MHz, DMSO-d $\left.\mathrm{d}_{6}\right): \delta_{\mathrm{c}} 110.5,117.5,120.3,136.8,142.1$, 152.5 and $167.7(\mathrm{C}-\mathrm{NH})$. MS (LCMS): $\mathrm{m} / \mathrm{z} 228\left(\mathrm{M}^{+}\right)$. Anal. calcd for $\mathrm{C}_{7} \mathrm{H}_{7} \mathrm{ClN}_{4} \mathrm{O}_{3} \mathrm{~S}$ (262.67): C, 32.01; H, 2.69; N, 21.33. Found: C, 31.95; H, 2.65; N, 21.23.

5-chloro-6-nitro and 5-sulfamoyl substituted ethyl-3-[2-(1,3-benzoxazol-2-yl) hydrazinylidene] butanoate (4a) and (4b)

Substituted 2-hydrazinyl-1,3-benzoxazole $(2.286 \mathrm{~g}, 0.01 \mathrm{~mol})(3 \mathrm{a}) /(3 \mathrm{~b})$ was taken in a $250 \mathrm{~mL}$ round-bottomed flask containing ethanol $(80 \mathrm{~mL})$ then, ethylacetoacetate $(1.4 \mathrm{~mL}, 0.01 \mathrm{~mol})$ was added and refluxed for 4 and $3 \mathrm{~h}$, respectively. The reaction mixture was poured on to crushed ice with constant stirring, which gave, $4 \mathbf{a}$ as light brown solid $(2.5 \mathrm{~g}, 73.51 \%), \mathrm{mp}$ above $285-287{ }^{\circ} \mathrm{C}$ and $\mathbf{4 b}$ as orange red solid (2.43 g, $71.45 \%$ ), mp 292-294 ${ }^{\circ} \mathrm{C}$ respectively. ethyl-3-[2-5-chloro-6-nitro(1,3-benzoxazol-2yl)hydrazinylidene] butanoate (4a): IR $\left(v_{\max } \mathrm{cm}^{-1}\right): 1529,590,1658,1710,1251 .{ }^{1} \mathrm{H} \mathrm{NMR}(400 \mathrm{MHz}$, DMSO-d $\left.)_{6}\right): \delta_{\mathrm{H}} 8.378(1 \mathrm{H}, \mathrm{s}), 7.677(1 \mathrm{H}, \mathrm{s}), 3.421\left(2 \mathrm{H}, \mathrm{s}, \mathrm{CH}_{2}-\mathrm{C}=\mathrm{O}\right), 4.096-4.149(2 \mathrm{H}, \mathrm{q}, J 7.131 \mathrm{~Hz}$, $\mathrm{CH}_{2}$ ester), $1.195-1.230\left(3 \mathrm{H}, \mathrm{t}, J 7.124 \mathrm{~Hz}, \mathrm{CH}_{3}\right), 2.034\left(3 \mathrm{H}, \mathrm{s}, \mathrm{CH}_{3}\right), 11.632(1 \mathrm{H}, \mathrm{s}, \mathrm{NH}$, disappeared on $\mathrm{D}_{2} \mathrm{O}$ exchange) ${ }^{13} \mathrm{C}$ NMR $\left(400 \mathrm{MHz}, \mathrm{DMSO}-\mathrm{d}_{6}\right): \delta_{\mathrm{c}} 14.9\left(\mathrm{CH}_{3}\right), 17.4\left(\mathrm{CH}_{3}\right), 43.7,61.0\left(\mathrm{OCH}_{2}\right), 112.8$, 116.6, 124.8, 140.5, 145.7, 152.1, 154.6, 157.5 and 168.1 $(\mathrm{C}=\mathrm{O})$. MS (LCMS): $m / z 341\left(\mathrm{M}^{+}\right), 343\left(\mathrm{M}^{+2}\right)$. Anal. calcd for $\mathrm{C}_{13} \mathrm{H}_{13} \mathrm{ClN}_{4} \mathrm{O}_{5}$ (340.71): C, 45.83; H, 3.85; N, 16.44. Found: C, 45.78; H, 3.80; N, 16.37. ethyl-3-[2-5-sulfamoyl(1,3-benzoxazol-2-yl)hydrazinylidene]butanoate (4b): IR ( $\left.v_{\max } \mathrm{cm}^{-1}\right): 1312$, 
1649, 1239. ${ }^{1} \mathrm{H}$ NMR (400 MHz, DMSO-d $): \delta_{\mathrm{H}} 7.335-7.838\left(3 \mathrm{H}, \mathrm{m}\right.$, aromatic), $2.187\left(2 \mathrm{H}, \mathrm{s}, \mathrm{CH}_{2}-\right.$ $\mathrm{C}=\mathrm{O}), 4.012$ - $4.135\left(2 \mathrm{H}, \mathrm{q}, J 7.0983 \mathrm{~Hz}, \mathrm{CH}_{2}\right.$ ester), $2.014-2.107\left(3 \mathrm{H}, \mathrm{t}, J 7.0979 \mathrm{~Hz}, \mathrm{CH}_{3}\right), 1.239(3 \mathrm{H}$, $\left.\mathrm{s}, \mathrm{CH}_{3}\right), 11.177\left(1 \mathrm{H}, \mathrm{s}, \mathrm{NH}\right.$, disappeared on $\mathrm{D}_{2} \mathrm{O}$ exchange $), 7.450\left(2 \mathrm{H}\right.$, s, sulfonamide $\mathrm{NH}_{2}$, disappeared on $\mathrm{D}_{2} \mathrm{O}$ exchange). ${ }^{13} \mathrm{C}$ NMR $\left(400 \mathrm{MHz}, \mathrm{DMSO}-\mathrm{d}_{6}\right): \delta_{\mathrm{c}} 14.5\left(\mathrm{CH}_{3}\right), 17.2\left(\mathrm{CH}_{3}\right), 45.1,62.0\left(\mathrm{OCH}_{2}\right)$, $110.8,120.2,124.7,138.5,145.6,150.1,152.4,154.5$ and $172.2(\mathrm{C}=\mathrm{O})$. MS (LCMS): $m / z 340\left(\mathrm{M}^{+}\right)$. Anal. calcd for $\mathrm{C}_{13} \mathrm{H}_{16} \mathrm{~N}_{4} \mathrm{O}_{5} \mathrm{~S}$ (340.35): C, 45.88; H, 4.74; N, 16.46. Found: C, 45.81; H, 4.69; N, 16.38.

\section{2-[2-(2,2-dicyanoethenyl)hydrazinyl]-1,3-benzoxazole-5-sulfonamide (5b)}

5-sulfamoyl substituted 2-hydrazinyl-1,3-benzoxazole $(2.286 \quad \mathrm{~g}, \quad 0.01 \quad \mathrm{~mol}) \quad(3 \mathrm{~b})$ and ethoxymethylene malononitrile $(1.22 \mathrm{~g}, 0.01 \mathrm{~mol})$ in dimethylformamide $(65 \mathrm{~mL})$ were refluxed for $2 \mathrm{~h}$. The reaction mixture was allowed to stand for few minutes and then poured onto crushed ice gives, $\mathbf{5 b}$ as pista greenish solid $(2.5 \mathrm{~g}, 82.16 \%), \mathrm{mp} 330-332{ }^{\circ} \mathrm{C}$. IR $\left(v_{\max } \mathrm{cm}^{-1}\right): 2221,3241,1324 .{ }^{1} \mathrm{H}$ NMR $(400$ MHz, DMSO-d $\left.{ }_{6}\right): \delta_{\mathrm{H}} 7.89(1 \mathrm{H}, \mathrm{d}, J$ 8.3648, CH), $8.01(1 \mathrm{H}, \mathrm{d}, J$ 8.5249), 8.12-8.22 (4H, m), $7.52(2 \mathrm{H}, \mathrm{s}$, sulfonamide $\mathrm{NH}_{2}$, disappeared on $\mathrm{D}_{2} \mathrm{O}$ exchange). ${ }^{13} \mathrm{C} \mathrm{NMR}\left(400 \mathrm{MHz}, \mathrm{DMSO}-\mathrm{d}_{6}\right): \delta_{\mathrm{c}} 56.5\left(\mathrm{C}(\mathrm{CN})_{2}\right)$, 111.2, $115.3(\mathrm{CN}), 119.7,123.5,135.4,141.2,151.6,165.4$ and 172.5. MS (LCMS): $\mathrm{m} / z$ 305 (M $\left.{ }^{+}\right)$. Anal. calcd for $\mathrm{C}_{11} \mathrm{H}_{8} \mathrm{~N}_{6} \mathrm{O}_{3} \mathrm{~S}$ (304.28): C, 43.42; H, 2.65; N, 27.62. Found: C, 43.35; H, 2.58; N, 27.55.

7-chloro-6-nitro and 7-sulfamoyl tetrazolo[5,1-b][1,3]benzoxazole (6a) and (6b)

Substituted 2-hydrazinyl-1,3-benzoxazole $(2.286 \mathrm{~g}, 0.01 \mathrm{~mol})(3 \mathrm{a}) /(3 \mathrm{~b})$ was taken in a $250 \mathrm{~mL}$ round-bottomed flask containing glacial acetic acid $(65 \mathrm{~mL})$ maintaining the temperature at $-5{ }^{\circ} \mathrm{C}$ by keeping it in ice bath. Then, sodium nitrite $(1.035 \mathrm{~g}, 0.015 \mathrm{~mol})$ was added to the solution dropwise. The reaction mixture was stirred for $30 \mathrm{~min}$. The reaction mixture was poured on to crushed ice with constant stirring, which gave, 6a as yellowish brown solid (1.92 g, $80.33 \%$ ), mp $182-184{ }^{\circ} \mathrm{C}$ and $\mathbf{6 b}$ as brown solid $(1.90 \mathrm{~g}, 79.5 \%)$, $\mathrm{mp} 180$ - $182{ }^{\circ} \mathrm{C}$, respectively. 7-chloro-6-nitro-tetrazolo[5,1b][1,3]benzoxazole (6a): IR $\left(v_{\max } \mathrm{cm}^{-1}\right): 2185,1524 .{ }^{1} \mathrm{H}$ NMR $\left(400 \mathrm{MHz}, \mathrm{DMSO}-\mathrm{d}_{6}\right): \delta_{\mathrm{H}} 8.622(1 \mathrm{H}, \mathrm{s})$, $8.108(1 \mathrm{H}, \mathrm{s}) .{ }^{13} \mathrm{C}$ NMR (400 MHz, DMSO-d $\left.{ }_{6}\right): \delta_{\mathrm{c}} 110.2,116.6,124.9,139.4,145.2,152.6$ and 159.3. MS (LCMS): $m / z 339\left(\mathrm{M}^{+}\right), 341\left(\mathrm{M}^{+2}\right)$. Anal. calcd for $\mathrm{C}_{7} \mathrm{H}_{2} \mathrm{ClN}_{5} \mathrm{O}_{3}$ (239.57): C, 35.09; $\mathrm{H}, 0.84 ; \mathrm{N}$, 29.23. Found: C, 35.05; H, 0.80; N, 29.18. 7-sulfamoyl-tetrazolo[5,1-b][1,3]benzoxazole (6b): IR ( $v_{\max }$ $\mathrm{cm}^{-1}$ ): 2140, 1608, 1356. ${ }^{1} \mathrm{H}$ NMR (400 MHz, DMSO-d 6 ): $\delta_{\mathrm{H}} 7.82-8.02(3 \mathrm{H}, \mathrm{m}), 7.47(2 \mathrm{H}$, s, sulfonamide $\mathrm{NH}_{2}$, disappeared on $\mathrm{D}_{2} \mathrm{O}$ exchange). ${ }^{13} \mathrm{C}$ NMR (400 MHz, DMSO-d $\left.\mathrm{d}_{6}\right): \delta_{\mathrm{c}} 111.8,118.7,123.7,138.3$, 142.4, 151.6 and 154.2. MS (LCMS): $m / z 339\left(\mathrm{M}^{+}\right)$. Anal. calcd for $\mathrm{C}_{7} \mathrm{H}_{5} \mathrm{~N}_{5} \mathrm{O}_{3} \mathrm{~S}$ (239.21): C, 35.15; $\mathrm{H}$, $2.11 ; \mathrm{N}, 29.28$. Found: C, 35.08; H, 2.05; N, 29.22.

\section{5-chloro-6-nitro and 5-sulfamoyl substituted 1,3-benzoxazol-2(3H)-one (7a) and (7b)}

Substituted 2-hydrazinyl-1,3-benzoxazole $(2.286 \mathrm{~g}, 0.01 \mathrm{~mol})(3 \mathrm{~A}) /(3 \mathrm{~B})$ was taken in a $100 \mathrm{~mL}$ round-bottomed flask. A $40 \mathrm{~mL}$ of formic acid/acetic acid was added along with a few drops of concentrated hydrochloric acid. It was refluxed for $3 \mathrm{~h}$. The reaction mixture was allowed to stand for few minutes and then it was poured onto crushed ice giving, 7a as yellowish green solid (1.93 $\mathrm{g}, 89.95 \%)$, mp $235-237{ }^{\circ} \mathrm{C}$ and $7 \mathbf{b}$ as brown solid (1.95 g, $90.88 \%$, mp $242-245{ }^{\circ} \mathrm{C}$, respectively. 5-chloro-6-nitro1,3-benzoxazol-2(3H)-one (7a): IR $\left(v_{\max } \mathrm{cm}^{-1}\right): 3260,2918,1767,1564,813 .{ }^{1} \mathrm{H} \mathrm{NMR}(400 \mathrm{MHz}$, DMSO- $\left.\mathrm{d}_{6}\right): \delta_{\mathrm{H}} 7.422$ to $8.288\left(2 \mathrm{H}, \mathrm{m}\right.$, aromatic), $11.40\left(1 \mathrm{H}, \mathrm{s}, \mathrm{NH}\right.$, disappeared on $\mathrm{D}_{2} \mathrm{O}$ exchange $) .{ }^{13} \mathrm{C}$ NMR (400 MHz, DMSO-d 6 ): $\delta_{\mathrm{c}} 120.31,124.32,126.48,135.27,144.11,148.27$ (benzoxazole) and 155.54 $(\mathrm{C}=\mathrm{O})$. MS (LCMS): $m / z 215\left(\mathrm{M}^{+}\right), 217\left(\mathrm{M}^{+2}\right)$. Anal. calcd for $\mathrm{C}_{7} \mathrm{H}_{3} \mathrm{ClN}_{2} \mathrm{O}_{4}$ (214.56): C, 39.18; $\mathrm{H}$, 1.41; N, 13.06. Found: C, 39.14; H, 1.38; N, 13.02. 5-sulfamoyl-1,3-benzoxazol-2(3H)-one (7b): IR $\left(v_{\max } \mathrm{cm}^{-1}\right): 3180,1750 .{ }^{1} \mathrm{H}$ NMR $\left(400 \mathrm{MHz}, \mathrm{DMSO}-\mathrm{d}_{6}\right): \delta_{\mathrm{H}} 7.441-7.578(3 \mathrm{H}, \mathrm{m}$, aromatic), $12.01(1 \mathrm{H}, \mathrm{s}$, $\mathrm{NH}$, disappeared on $\mathrm{D}_{2} \mathrm{O}$ exchange), $7.38\left(2 \mathrm{H}\right.$, s, sulfonamide $\mathrm{NH}_{2}$, disappeared on $\mathrm{D}_{2} \mathrm{O}$ exchange). ${ }^{13} \mathrm{C}$ NMR $\left(400 \mathrm{MHz}, \mathrm{DMSO}-\mathrm{d}_{6}\right): \delta_{\mathrm{c}} 121.35,123.63,124.69,131.54,133.11,138.72(\mathrm{C}$ benzoxazole) and $141.45(\mathrm{C}=\mathrm{O})$. MS (LCMS): $m / z 215\left(\mathrm{M}^{+}\right)$. Anal. calcd for $\mathrm{C}_{7} \mathrm{H}_{6} \mathrm{~N}_{2} \mathrm{O}_{4} \mathrm{~S}$ (214.19): $\mathrm{C}, 39.25 ; \mathrm{H}, 2.82 ; \mathrm{N}$, 13.08. Found: C, 39.21; H, 2.79; N, 13.03.

\section{Results and discussion}

\section{In silico studies}

The newly synthesized benzoxazole nucleus derivatives (1a, 1b, 2a, 2b, 3a, 3b, 4a, 4b, 5b, 6a, 6b, 7a and 7b) were docked against target Human pancreatic alpha-amylase (PDB ID: 3BAW) [16] using AutoDoc 4.2 platform. The binding energies of the same is tabulated in Table 1. The study was made to find the possible binding mode and interaction of molecules with amino acid residues. Initial structure optimization and energy minimization of all ligands were carried out using OpenBabel 2.3.2 [17], 
followed by the addition of Gasteiger charges along with polar hydrogen atoms. An objective-based docking technique was utilized in this investigation to set up the grid maps framework. The lattice points of the grid box (spacing 0.375) and grid centre of maps was set at $X=58, Y=48, Z=48$ and $x=14.919$, $y=-17.939, z=-22.527$, respectively. ADT scoring function was used for the determination of Ligand binding affinity, and it was anticipated as negative Gibbs free energy $(\Delta \mathrm{G})(\mathrm{Kcal} / \mathrm{mol})$. On the basis of the binding energy and the formation of hydrogen bonds, the nature of the interaction, whether strong, medium or low, was determined. The posture with the highest negative value was regarded as the best conformation. DS Visualizer (v21.1.0.20298) has been used to perform post-docking analysis.

Table 1 Binding energies by Molecular docking studies to the compounds against Human pancreatic alpha-amylase (PDB ID: 3BAW).

\begin{tabular}{ccccccccccccccc}
\hline Compound & $1 \mathrm{a}$ & $1 \mathrm{~b}$ & $2 \mathrm{a}$ & $2 \mathrm{~b}$ & $3 \mathrm{a}$ & $3 \mathrm{~b}$ & $4 \mathrm{a}$ & $4 \mathrm{~b}$ & $\mathbf{5 b}$ & $6 \mathrm{a}$ & $\mathbf{6 b}$ & $7 \mathrm{a}$ & $7 \mathrm{~b}$ & Acarbose \\
\hline $\begin{array}{c}\text { Binding } \\
\text { energy } \\
\text { (kcal/mol) }\end{array}$ & -6.32 & -6.04 & -7.04 & -6.73 & -6.12 & -6.77 & -6.54 & -7.08 & $-\mathbf{8 . 1 2}$ & -5.98 & $-\mathbf{8 . 0 0}$ & -5.15 & -6.78 & $-\mathbf{1 1 . 2 7}$ \\
\hline
\end{tabular}

(a)

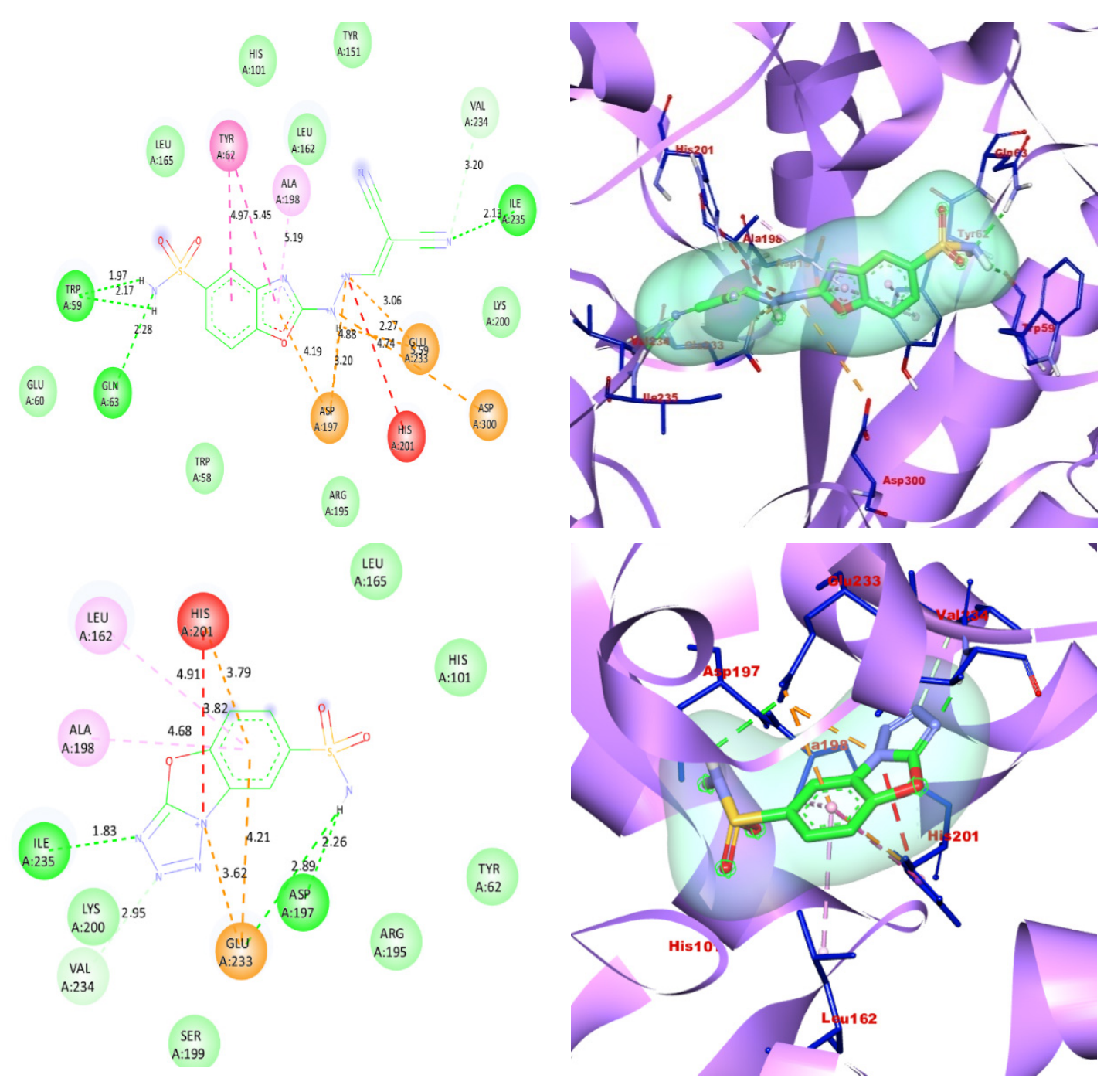


(c)
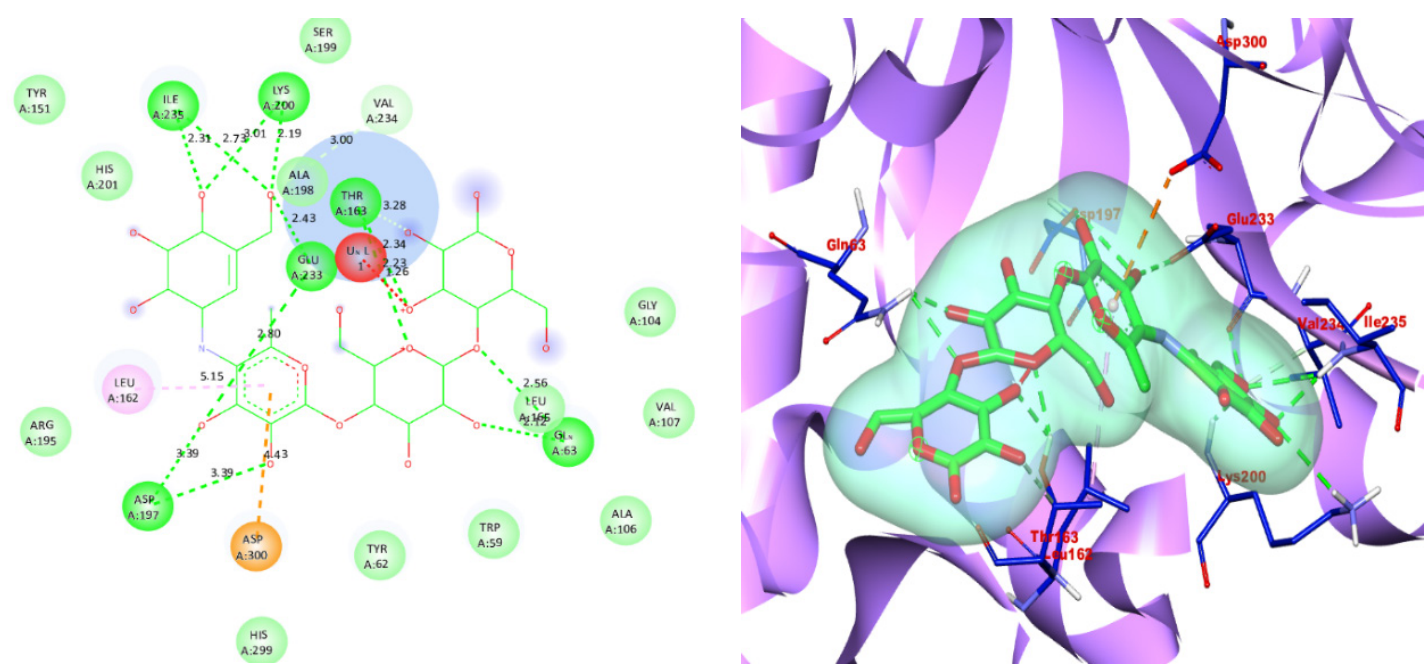

Figure 1 Molecular docking analysis of lead compounds 5b (a) and 6b (b) compared with acarbose (c) against Human pancreatic alpha-amylase.

Among the 13 molecules, it was found that the binding energy of molecules $\mathbf{5 b}, \mathbf{6 b}, \mathbf{3 b}$ and $\mathbf{4 b}$ was the lowest viz, $\mathbf{- 8 . 1 2}, \mathbf{- 8 . 0 0}, \mathbf{- 6 . 7 7}$ and $\mathbf{- 7 . 0 8}$ by exhibiting $2,4,1$ and 3 hydrogen bonds, respectively (Table 2). In the active pocket, amino acid residues ASP300, GLN63, THR163, ARG195, ASP197, ILE235, TRP59, GLN63, GLN63, LYS200, GLU233 and THR163 formed the Hydrogen bonds with Human pancreatic alpha-amylase. The hydrogen and hydrophobic interaction profile of molecules $\mathbf{5} \mathbf{b}$ and 6b with the receptor, and their distances are shown in Figure 1. From the present study, it can be suggested that $\mathbf{5 b}$ and $\mathbf{6 b}$ ligand molecules can show better inhibition. In this context, all synthesized molecules were further subjected to anti-diabetic experimental validation to confirm these findings.

Table 2 Molecular docking results of lead compounds compared with acarbose against Human pancreatic alpha-amylase.

\begin{tabular}{ccccc}
\hline \multirow{2}{*}{$\begin{array}{c}\text { Lead } \\
\text { compounds }\end{array}$} & $\begin{array}{c}\text { Binding energy } \\
\mathbf{( k c a l / m o l )}\end{array}$ & $\begin{array}{c}\text { No. of H- } \\
\text { bonds }\end{array}$ & Amino acid residues & Distance $(\mathbf{A})$ \\
\cline { 3 - 5 } & -6.77 & 1 & ASP300 & 2.14 \\
\hline $\mathrm{b}$ & -7.08 & 3 & GLN63, THR163, ARG195 & $2.17,1.97,1.66$ \\
$4 \mathrm{~b}$ & -8.12 & 2 & ASP197; ILE235 & $2.26 ; 1.83$ \\
$\mathbf{5 b}$ & -8.00 & 4 & ILE235; TRP59; GLN63 & $2.13 ; 2.17 ; 1.97 ; 2.28$ \\
$\mathbf{6 b}$ & -11.27 & 10 & ASP197; GLN63; LYS200; & $3.39 ; 2.56 ; 2.12 ; 2.19 ;$ \\
& & & ILE235; GLU233; THR163 & $3.01 ; 2.73 ; 2.31 ; 2.80 ;$ \\
Acarbose & & & & 2.34 \\
\hline
\end{tabular}

\section{Biological studies}

The synthesized 13 compounds were screened for 3 different varieties of antioxidant activity, and 2 different methodologies were employed for antidiabetic activity. Antioxidant activity was performed by DPPH assay, Total antioxidant \& Reducing power method whereas antidiabetic activity was carried out by alpha-amylase $\&$ alpha-glucosidase assay. 


\section{In-vitro antioxidant studies}

DPPH assay: The method by Brand-William et al. [18] was used to calculate the compound's radical scavenging behavior against stable 2,2-diphenyl 2-picrylhydrazyl hydrate (DPPH). DPPH was reduced when it came into contact with an antioxidant compound that could donate hydrogen. On a UV visible spectrophotometer, the color transition (from dark violet to pale yellow) was measured at an optical density of $515 \mathrm{~nm}$.

The standard reference for the DPPH test was ascorbic acid. Distilled water was used for the preparation of stock solution by ascorbic acid $(1 \mathrm{mg} / \mathrm{mL} ; \mathrm{w} / \mathrm{v})$. A $60 \mu \mathrm{M}$ solution of DPPH in methyl alcohol was freshly prepared and $3.9 \mathrm{~mL}$ of this solution was mixed with $100 \mu \mathrm{L}$ of the test sample at several concentrations $(6.25,12.5,25,50$ and $100 \mu \mathrm{g} / \mathrm{mL})$. The test tubes were kept in the dark for 15 minutes at room temperature and then the change in absorbance was measured at $515 \mathrm{~nm}$. The control was made using only DPPH solution, no extract, and no ascorbic acid. $95 \%$ methyl alcohol was used as a blank solution. The radical scavenging behavior was calculated using the formula below.

Percentage inhibition $=\frac{(\text { Absorbance of Control at } 0 \text { min }- \text { Absorbance of test }) \times 100}{\text { Absorbance of control at } 15 \mathrm{~min}}$

Table 3 Absorbance of the synthesized compound at $515 \mathrm{~nm}$ for DPPH assay.

\begin{tabular}{|c|c|c|c|c|c|}
\hline \multirow{2}{*}{ Compound / Concentrations } & $6.25 \mu \mathrm{g} / \mathrm{mL}$ & $12.5 \mu \mathrm{g} / \mathrm{mL}$ & $25 \mu \mathrm{g} / \mathrm{mL}$ & $50 \mu \mathrm{g} / \mathrm{mL}$ & $100 \mu \mathrm{g} / \mathrm{mL}$ \\
\hline & \multicolumn{5}{|c|}{ OD at $515 \mathrm{~nm}$} \\
\hline $1 \mathrm{a}$ & 0.684 & 0.607 & 0.489 & 0.335 & 0.094 \\
\hline $1 b$ & 0.700 & 0.472 & 0.291 & 0.092 & 0.058 \\
\hline $2 \mathrm{a}$ & 0.589 & 0.520 & 0.290 & 0.150 & 0.093 \\
\hline $2 b$ & 0.599 & 0.463 & 0.288 & 0.156 & 0.092 \\
\hline $3 a$ & 0.687 & 0.619 & 0.499 & 0.290 & 0.099 \\
\hline $3 b$ & 0.596 & 0.447 & 0.268 & 0.101 & 0.085 \\
\hline $4 a$ & 0.606 & 0.466 & 0.358 & 0.292 & 0.147 \\
\hline $4 b$ & 0.598 & 0.526 & 0.283 & 0.154 & 0.084 \\
\hline $5 b$ & 0.540 & 0.407 & 0.142 & 0.085 & 0.055 \\
\hline $6 a$ & 0.698 & 0.634 & 0.517 & 0.325 & 0.128 \\
\hline $6 b$ & 0.553 & 0.430 & 0.184 & 0.120 & 0.072 \\
\hline $7 \mathrm{a}$ & 0.697 & 0.640 & 0.533 & 0.358 & 0.119 \\
\hline $7 b$ & 0.604 & 0.459 & 0.294 & 0.140 & 0.076 \\
\hline Ascorbic acid & 0.629 & 0.494 & 0.334 & 0.066 & - \\
\hline Control at $0 \mathrm{~min}$ & & & 0.747 & & \\
\hline Control at $15 \mathrm{~min}$ & & & 0.701 & & \\
\hline
\end{tabular}




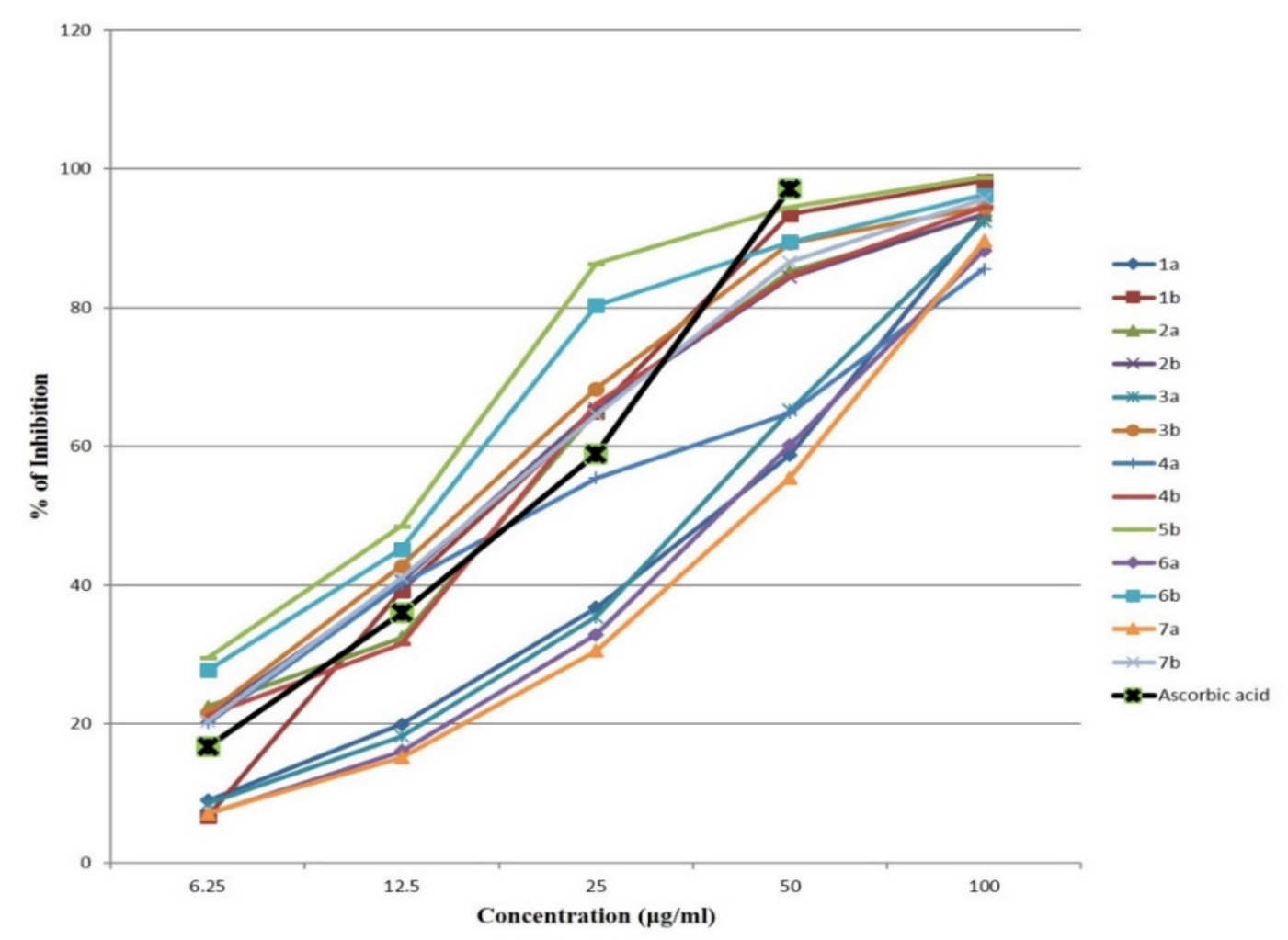

Figure 2 Inhibition of compounds in DPPH assay.

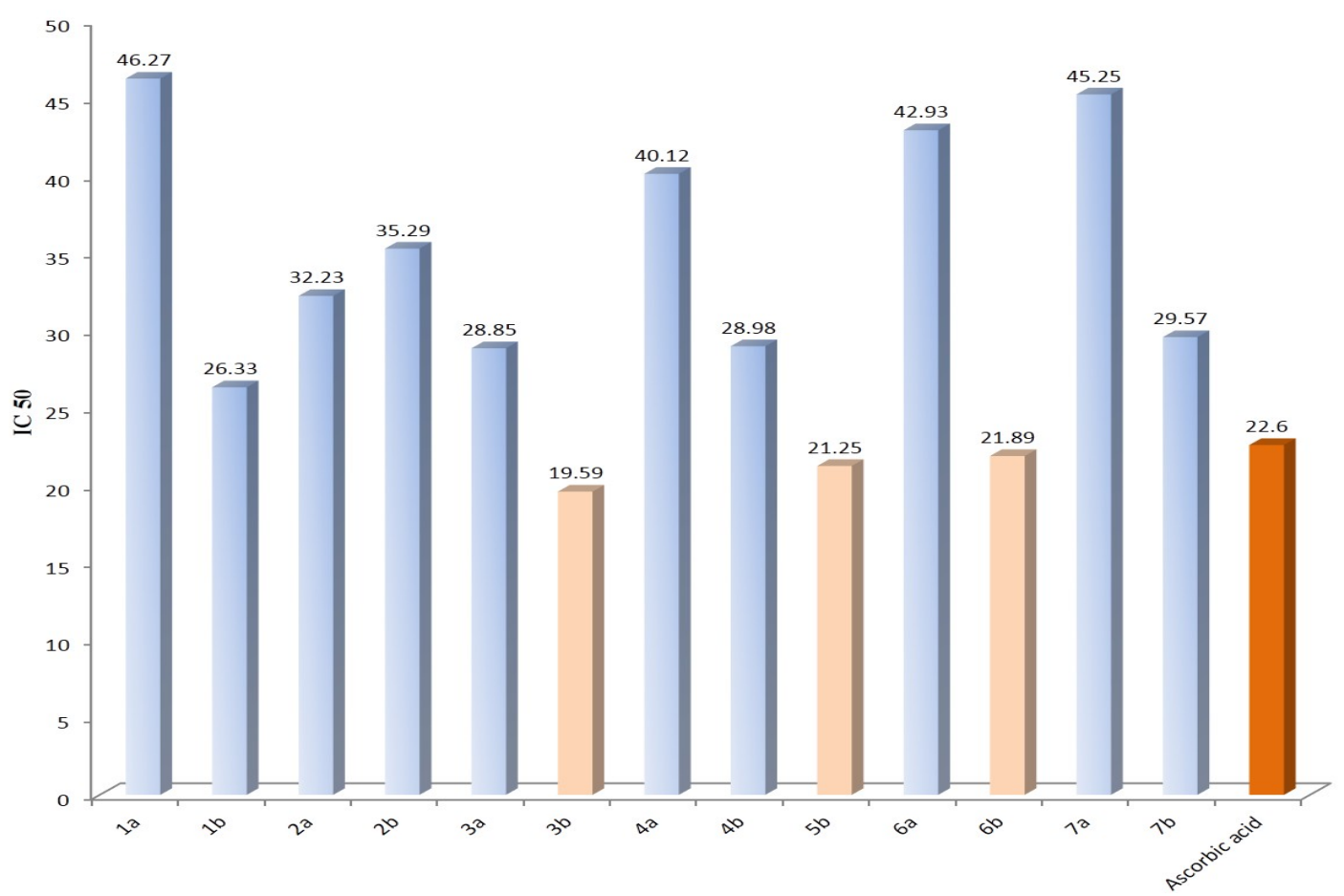

Figure 3 Comparison of IC 50 values of synthesized compounds. 
All synthesized compounds have shown the capacity for scavenging the free radical when compared with the standard Ascorbic acid. \% of inhibition was plotted against different concentrations (6.25, 12.5, 25, 50 and $100 \mu \mathrm{g} / \mathrm{mL}$ ) in Figure 2. IC 50 values of all the compounds are shown in Figure 3. The absorbance (Optical density) for all compounds at $515 \mathrm{~nm}$ was tabulated in Table 3. With all the above data out of 13 compounds, $\mathbf{5 b}$ and $\mathbf{6 b}$ showed potent activity followed by $\mathbf{4 b}$ and $\mathbf{3 b}$ when compared with standard ascorbic acid.

\section{Total antioxidant activity (phospho-molybdenum test)}

The phospho-molybdenum method was used to determine the compound's total antioxidant ability. It is on the basis of compounds reducing Mo (VI) to Mo (V) and then forming a Mo(V) complex of green phosphate at a $\mathrm{pH}$ of acidic. It quantifies antioxidants that are both water-soluble and fat-soluble (total antioxidant capacity).

$1 \mathrm{mg} / \mathrm{mL}$ of sample was mixed with $3 \mathrm{~mL}$ of reagent solution $(28 \mathrm{mM}$ sodium phosphate, $0.6 \mathrm{M}$ sulfuric acid and $4 \mathrm{mM}$ ammonium molybdate) as per the protocol designated by Prieto et al. [19]. The standard was ascorbic acid and $1 \mathrm{~mL}$ of different concentrations of the standard were mixed with $3 \mathrm{~mL}$ of reagent solution. The reaction solution was incubated for $90 \mathrm{~min}$ at $95{ }^{\circ} \mathrm{C}$ in test tubes. After cooling at room temperature, the optical density of the solution was measured against a blank with a UV-VIS spectrophotometer at $695 \mathrm{~nm}$. The number of gram equivalents of ascorbic acid is used to measure overall antioxidant activity. Ascorbic acid and methyl alcohol were mixed together to create the calibration curve.

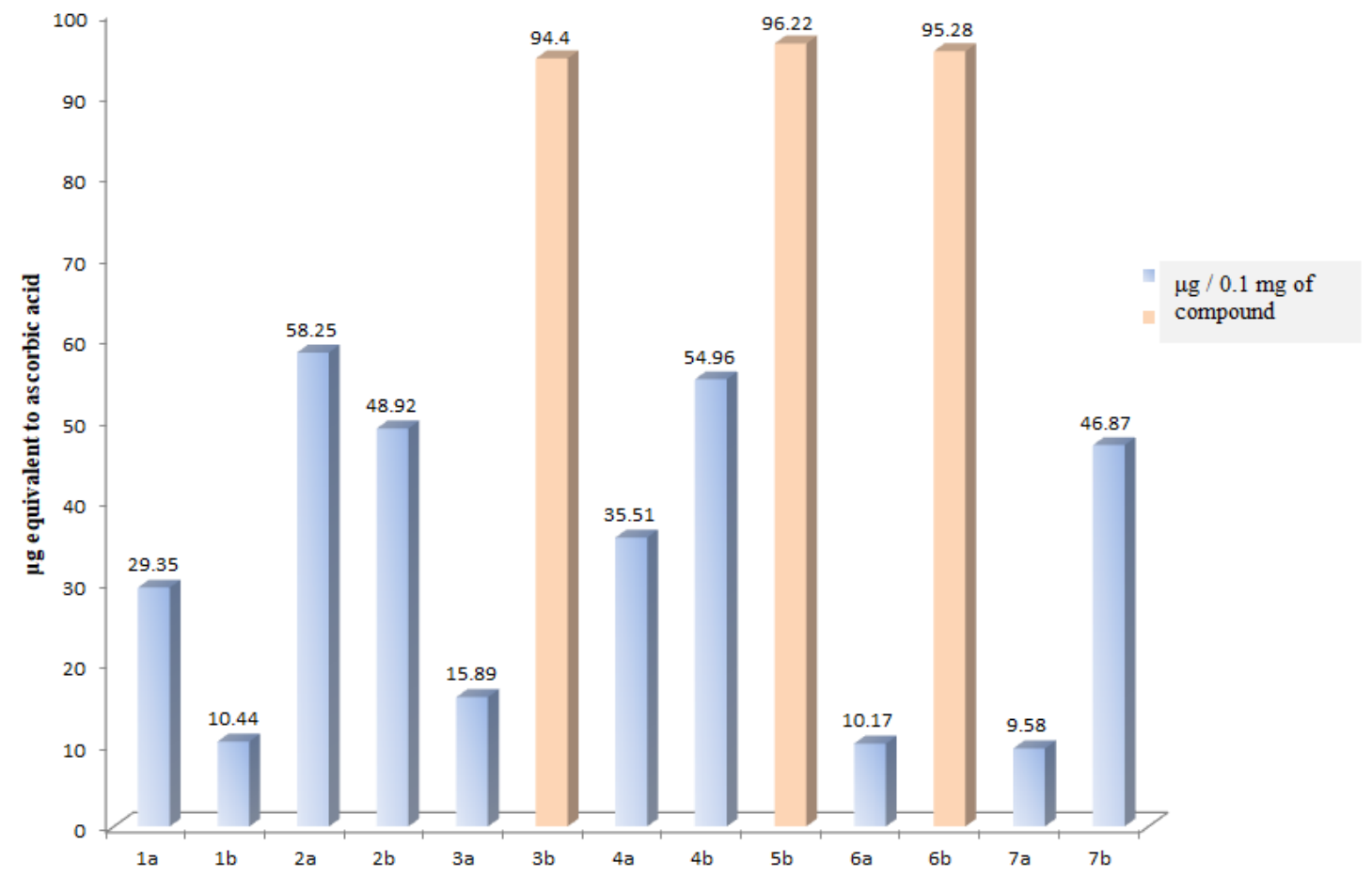

Figure 4 Total antioxidant capacity of compounds.

The total antioxidant capacities are well expressed as gram equivalents of ascorbic acid. Amongst the 13 compounds, $\mathbf{5 b}, \mathbf{6 b}$ and $\mathbf{3 b}$ showed good antioxidant action as equivalents to ascorbic acid. Figure 4 gives the outcomes of $\mu \mathrm{g}$ equivalent to ascorbic acid to each of the tested compounds.

\section{Reducing power method}

The Oyaizu [20] method was used to evaluate the compounds reducing strength. The compounds were combined with $1.25 \mathrm{~mL}$ of $1 \%$ potassium ferricyanide and $1.2 \mathrm{~mL}$ of sodium phosphate buffer $(\mathrm{pH}$ 6.6) at different concentrations $(6.25,12.5,25,50$ and $100 \mu \mathrm{g})$. For $20 \mathrm{~min}$, the mixture was incubated at $50{ }^{\circ} \mathrm{C}$. Upon incubation, $1.25 \mathrm{~mL}$ of $10 \%$ trichloroacetic acid (w/v) was added, followed by a $10-\mathrm{min}$ 
centrifugation. The absorbance of the top layer $(1 \mathrm{~mL})$ was estimated at $700 \mathrm{~nm}$ after it was combined with $1 \mathrm{~mL}$ of distilled water and $125 \mu \mathrm{L}$ of $0.1 \%$ ferric chloride (w/v). For set 0 , a negative control (Reagent Blank) was used.

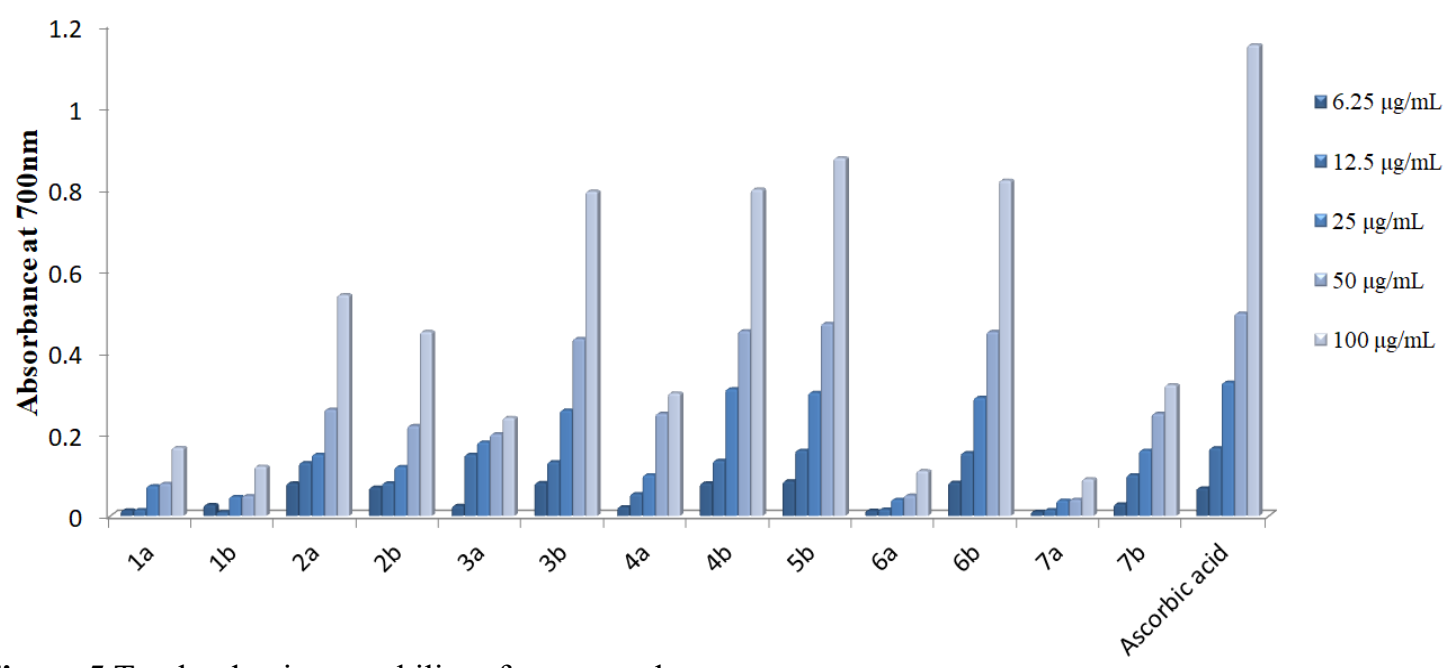

Figure 5 Total reductive capability of compounds.

The reducing powers of the compounds were compared with standard ascorbic acid. Among the 13 tested compounds, compound $\mathbf{5 b}$ showed higher absorbance indicating higher reducing power, followed by $\mathbf{6 b}, \mathbf{4 b}$ and $\mathbf{3 b}$, whereas $7 \mathbf{a}$ and $\mathbf{6 a}$ showed very little absorbance. The results are given in Figure 5.

\section{In-vitro Anti-diabetic studies}

a-glucosidase inhibition assay

According to Kim et al. [21] procedure, the inhibitory activity of the sample on the $\alpha$-glucosidase enzyme was determined. For $10 \mathrm{~min}, 200 \mu \mathrm{L}$ of diluted $\alpha$-glucosidase $(0.067 \mathrm{U} / \mathrm{mL})$ were pre-incubated with varying concentrations of the sample. In $0.1 \mathrm{M}$ sodium phosphate buffer of $\mathrm{pH} 6.9$, the substrate solution pNPG (p-nitrophenyl $\alpha$-D-glucopyranoside) was developed. To begin the reaction, $200 \mu \mathrm{L}$ of 3.0 $\mathrm{mM}$ pNPG was prepared as the substrate in $0.1 \mathrm{M}$ sodium phosphate buffer. At $37{ }^{\circ} \mathrm{C}$ the reaction solution was incubated for $20 \mathrm{~min}$ before being stopped with $2 \mathrm{~mL}$ of $0.1 \mathrm{M} \mathrm{Na}_{2} \mathrm{CO}_{3}$. The yellow-colored para-nitro phenol released from pNPG was measured at $400 \mathrm{~nm}$ to determine the $\alpha$-glucosidase activity.

The percentage of inhibition was used to express the effect on the molecules in the results. The same procedure was done with Acarbose $(1 \mathrm{mg} / \mathrm{mL})$ which was used as standard. The \% of Inhibitory activity was calculated by the below formula;

Inhibitory activity $(\%)=(B-T / B-C) \times 100$

where, B is the absorbance of blank,

$\mathrm{T}$ is the absorbance in the presence of test substance,

$\mathrm{C}$ is the absorbance of control. 


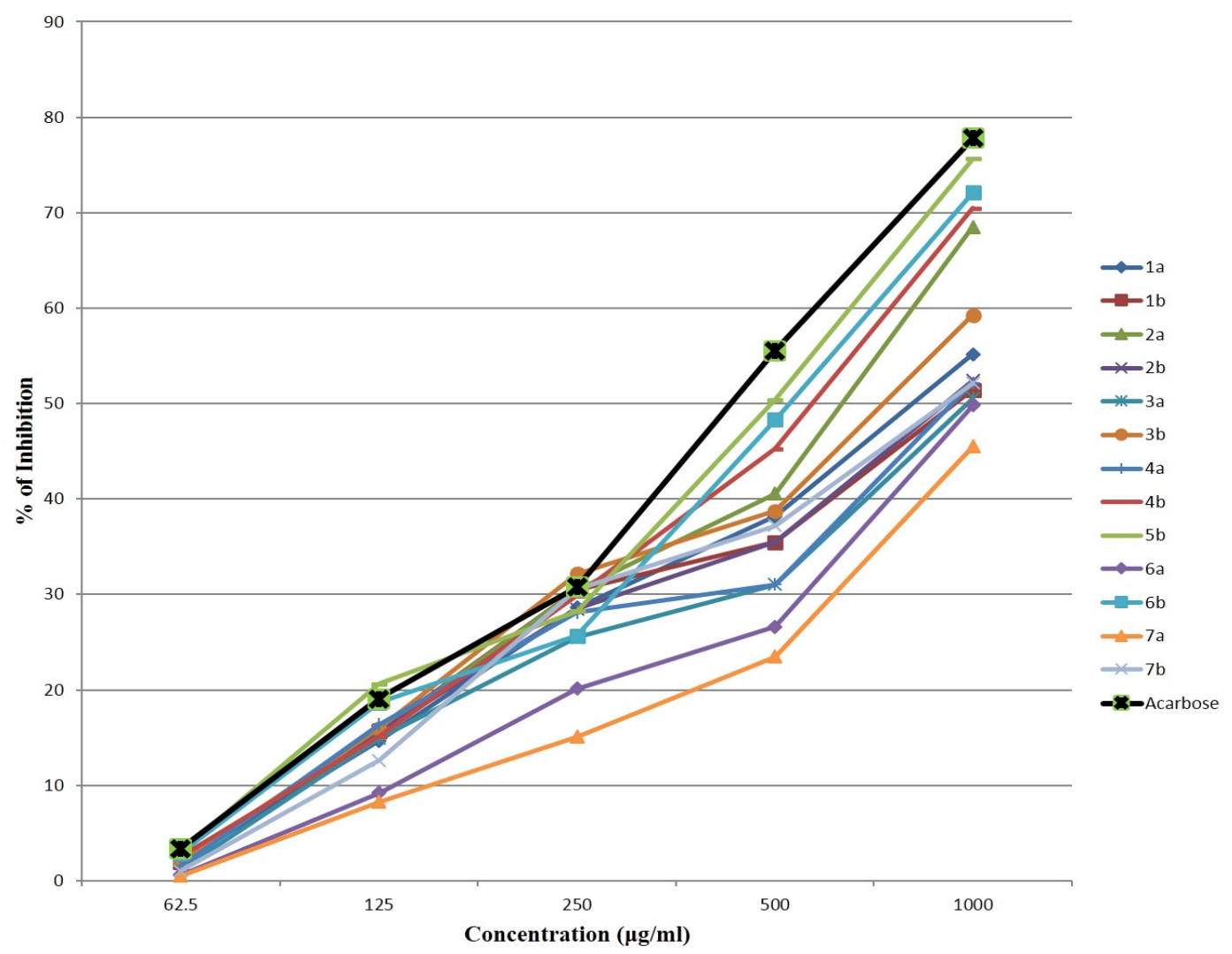

Figure $6 \alpha$-glucosidase inhibition of compounds.

In Figure 6, \% of Inhibition of all synthesized compounds were plotted against different concentrations $(62.5,125,250,500$ and $1000 \mu \mathrm{g} / \mathrm{mL})$ and compared with standard drug Acarbose. Compounds absorbance at $400 \mathrm{~nm}$ were tabulated in Table 4.

Table 4 Absorbance of the synthesized compound at $400 \mathrm{~nm}$ for $\alpha$-Glucosidase inhibition assay.

\begin{tabular}{|c|c|c|c|c|c|}
\hline \multirow{2}{*}{ Compound / Concentrations } & $62.5 \mu \mathrm{g} / \mathrm{mL}$ & $125 \mu \mathrm{g} / \mathrm{mL}$ & $250 \mu \mathrm{g} / \mathrm{mL}$ & $500 \mu \mathrm{g} / \mathrm{mL}$ & $1000 \mu \mathrm{g} / \mathrm{mL}$ \\
\hline & \multicolumn{5}{|c|}{ OD at $400 \mathrm{~nm}$} \\
\hline $1 \mathrm{a}$ & 0.855 & 0.745 & 0.625 & 0.542 & 0.395 \\
\hline $1 b$ & 0.855 & 0.737 & 0.608 & 0.565 & 0.427 \\
\hline $2 \mathrm{a}$ & 0.854 & 0.738 & 0.608 & 0.521 & 0.279 \\
\hline $2 b$ & 0.856 & 0.737 & 0.626 & 0.565 & 0.419 \\
\hline $3 a$ & 0.862 & 0.743 & 0.652 & 0.603 & 0.435 \\
\hline $3 b$ & 0.855 & 0.734 & 0.594 & 0.537 & 0.359 \\
\hline $4 a$ & 0.859 & 0.730 & 0.629 & 0.603 & 0.421 \\
\hline $4 b$ & 0.850 & 0.741 & 0.614 & 0.480 & 0.263 \\
\hline $5 b$ & 0.845 & 0.694 & 0.628 & 0.436 & 0.218 \\
\hline $6 a$ & 0.867 & 0.792 & 0.698 & 0.642 & 0.441 \\
\hline $6 b$ & 0.847 & 0.711 & 0.650 & 0.454 & 0.248 \\
\hline $7 a$ & 0.867 & 0.801 & 0.741 & 0.669 & 0.479 \\
\hline $7 b$ & 0.863 & 0.763 & 0.608 & 0.550 & 0.421 \\
\hline Acarbose & 0.843 & 0.707 & 0.606 & 0.392 & 0.199 \\
\hline Blank & & & 0.872 & & \\
\hline Control & & & 0.007 & & \\
\hline
\end{tabular}


Out of all the compounds tested, $\mathbf{5 b}$ and $\mathbf{6 b}$ showed good inhibition with reference to standard acarbose. However, 7a and $\mathbf{6 a}$ were less active towards the $\alpha$-glucosidase inhibition assay when compared with all the tested compounds.

\section{$\alpha$-amylase inhibitory assay by DNSA method}

The anti-diabetic action of the test samples was determined according to the method described in the Worthington Enzyme Manual with slight modifications [22,23]. In brief, $500 \mu \mathrm{L}$ of $0.02 \mathrm{M} \mathrm{Na}_{3} \mathrm{PO}_{4}$ buffer of $\mathrm{pH} 6.9$ with $0.006 \mathrm{M} \mathrm{NaCl}$ containing $0.5 \mathrm{mg} / \mathrm{mL}$ of $\alpha$-amylase enzyme and different concentrations (in $\mu \mathrm{g}$ ) of the test sample as enzyme inhibitor were pre-incubated at $37^{\circ} \mathrm{C}$ for $10 \mathrm{~min}$. After the preincubation, each test tube was filled with $500 \mu \mathrm{L}$ of a $1 \%$ starch solution in $0.02 \mathrm{M} \mathrm{Na}_{3} \mathrm{PO}_{4}$ buffer of pH 6.9 and incubated at room temperature for $5 \mathrm{~min} .1 .0 \mathrm{~mL}$ of dinitrosalicylic acid (DNSA) reagent was used to avoid the reaction.

After the pre-incubation, $500 \mu \mathrm{L}$ of a $1 \%$ starch solution in $0.02 \mathrm{M}$ sodium phosphate buffer $(\mathrm{pH}$ 6.9) was added to each tube and incubated at room temperature for $5 \mathrm{~min}$. The reaction was stopped using $1.0 \mathrm{~mL}$ of dinitrosalicylic acid (DNSA) reagent. The test tubes were heated for $5 \mathrm{~min}$ in boiling water and then cooled at ambient temperature. By adding distilled water to the reaction mixture, the volume was increased to $10 \mathrm{~mL}$. The UV-Visible spectrophotometer was used at $540 \mathrm{~nm}$, and the optical density of the compound was measured. The control sample and blank was taken for comparison for the absorbance of test compounds. The percentage of inhibition for the test sample is expressed below;

Percentage inhibition $=\frac{(\mathrm{B}-\mathrm{A}) \times 100}{(\mathrm{~B}-\mathrm{C})}$

where, C - Absorbance of the control with starch and without alpha-amylase,

B - Absorbance of the control with starch and alpha-amylase,

A - Absorbance of the test.

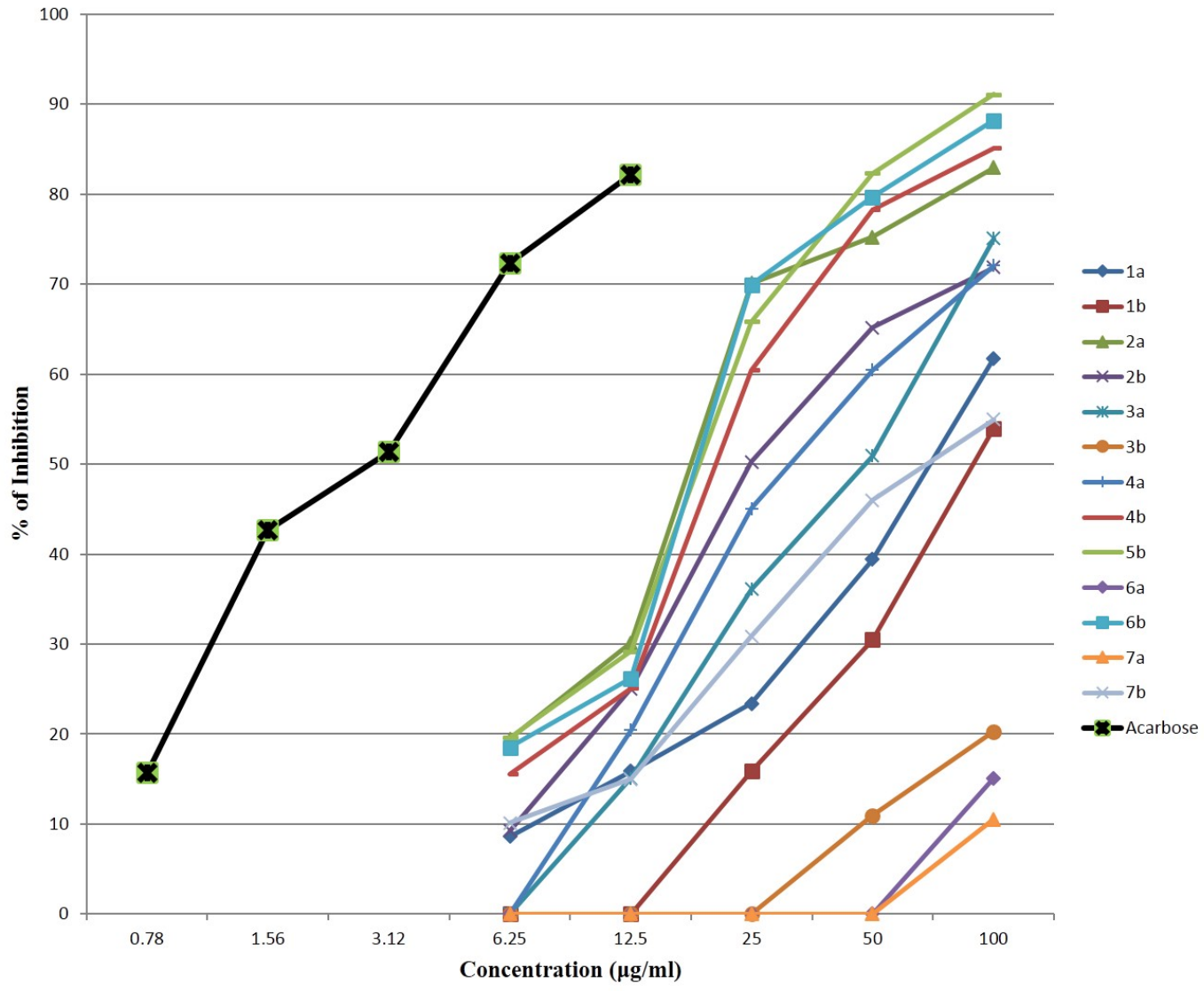

Figure $7 \alpha$-amylase inhibitory capacity of compounds. 
In the Figure 7, \% of Inhibition of all synthesized compounds were plotted against different concentrations $(0.78,1.56,3.12,6.25,12.5,25,50$ and $100 \mu \mathrm{g} / \mathrm{mL})$ and compared with standard drug Acarbose.

Table 5 Absorbance of the synthesized compound at $540 \mathrm{~nm}$ for $\alpha$-amylase inhibition assay.

\begin{tabular}{|c|c|c|c|c|c|}
\hline \multirow{2}{*}{ Compound / Concentrations } & $6.25 \mu \mathrm{g} / \mathrm{mL}$ & $12.5 \mu \mathrm{g} / \mathrm{mL}$ & $25 \mu \mathrm{g} / \mathrm{mL}$ & $50 \mu \mathrm{g} / \mathrm{mL}$ & $100 \mu \mathrm{g} / \mathrm{mL}$ \\
\hline & \multicolumn{5}{|c|}{ OD at $540 \mathrm{~nm}$} \\
\hline $1 \mathrm{a}$ & 0.994 & 0.918 & 0.840 & 0.673 & 0.441 \\
\hline $1 b$ & - & - & 0.918 & 0.766 & 0.522 \\
\hline $2 \mathrm{a}$ & 0.881 & 0.770 & 0.355 & 0.301 & 0.221 \\
\hline $2 b$ & 0.987 & 0.823 & 0.561 & 0.406 & 0.336 \\
\hline $3 a$ & - & 0.926 & 0.708 & 0.554 & 0.303 \\
\hline $3 b$ & - & - & - & 0.969 & 0.872 \\
\hline $4 a$ & - & 0.871 & 0.615 & 0.455 & 0.334 \\
\hline $4 b$ & 0.921 & 0.822 & 0.455 & 0.270 & 0.198 \\
\hline $5 b$ & 0.879 & 0.780 & 0.399 & 0.227 & 0.137 \\
\hline $6 a$ & - & - & - & - & 0.926 \\
\hline $6 b$ & 0.891 & 0.811 & 0.356 & 0.255 & 0.167 \\
\hline $7 \mathrm{a}$ & - & - & - & - & 0.973 \\
\hline $7 \mathrm{~b}$ & 0.978 & 0.927 & 0.763 & 0.605 & 0.512 \\
\hline Blank & & & 1.083 & & \\
\hline \multirow[t]{3}{*}{ Control } & & & 0.044 & & \\
\hline & \multicolumn{5}{|c|}{ OD at $540 \mathrm{~nm}$} \\
\hline & $0.78 \mu \mathrm{g} / \mathrm{mL}$ & $1.56 \mu \mathrm{g} / \mathrm{mL}$ & $3.12 \mu \mathrm{g} / \mathrm{mL}$ & $6.25 \mu \mathrm{g} / \mathrm{mL}$ & $12.5 \mu \mathrm{g} / \mathrm{mL}$ \\
\hline Acarbose & 0.601 & 0.439 & 0.387 & 0.261 & 0.202 \\
\hline Blank & & & 0.695 & & \\
\hline Control & & & 0.095 & & \\
\hline
\end{tabular}

The absorbance of the tested compound at $540 \mathrm{~nm}$ has been tabulated in Table 5. Out of all the compounds tested, $\mathbf{5 b}$ and $\mathbf{6 b}$ showed a near percentage of inhibition with reference to standard acarbose.

\section{Conclusions}

In the present work, biologically important sulfonamide functionality was considered while synthesizing benzoxazole derivatives to evaluate the probability of an increase in potency of the benzoxazole nucleus. As per the expectation, the benzoxazole molecules having sulfonamide functionality stood out in the activities performed.

Among the 13 molecules, $\mathbf{5 b}, \mathbf{6 b}$ and $\mathbf{3 b}$ showed significant results for subjected antioxidant and anti-diabetic activity. In the DPPH assay, below $50 \mu \mathrm{g} / \mathrm{ml}$, compounds $\mathbf{5 b}, \mathbf{6 b}$ and $\mathbf{3 b}$ outperformed in comparison with the standard ascorbic acid and IC50 values were on par with the standard. The total antioxidant capacity study also showed as the molecules $\mathbf{3 b}, \mathbf{5 b}$ and $\mathbf{6 b}$ were equivalent to ascorbic acid. In anti-diabetic activity i.e., $\alpha$-glucosidase and $\alpha$-amylase inhibitory assay, molecule, $5 \mathbf{b}, \mathbf{6 b}$ and $\mathbf{4 b}$ emerged as potent anti-diabetic compounds in comparison with the standard acarbose.

The results of in silico studies carried out for anti-diabetic assay also compliments the in-vitro studies. The presence of the sulfonamide group is a common factor in $\mathbf{3 b}, \mathbf{4 b}, \mathbf{5 b}$ and $\mathbf{6} \mathbf{b}$ molecules. In comparison with standard drug ascorbic acid and acarbose, these molecules also contain oxygen and nitrogen atoms that are responsible for hydrogen bonding. The small 3-dimensional stable structure increases the permeability and its ability to form hydrogen bonding. The molecule shows good activity towards antioxidant and anti-diabetic. In progress to the current work, the potent molecules are subjected to cytotoxicity and specific organ toxicity.

\section{Acknowledgements}

The Author acknowledges UGC for the Maulana Azad National Fellowship, The Indian Institute of Science (IISc), Bangalore and Manipal Institute of Technology (MIT), Manipal for ${ }^{1} \mathrm{H}$ and ${ }^{13} \mathrm{C}$ NMR analysis. 


\section{References}

[1] J Montonen, P Knekt, R Järvinen and A Reunanen. Dietary antioxidant intake and risk of type 2 diabetes. Diabetes Care 2004; 27, 362-6.

[2] RV Satyendra, KA Vishnumurthy, HM Vagdevi, KP Rajesh, H Manjunatha and A Shruthi. Synthesis, in vitro antioxidant, anthelmintic and molecular docking studies of novel dichloro substituted benzoxazole-triazolo-thione derivatives. Eur. J. Med. Chem. 2011; 46, 3078-84.

[3] M Kale and V Chavan. Exploration of the biological potential of benzoxazoles: An overview. Mini Rev. Org. Chem. 2018; 16, 111-26.

[4] AP Keche and VM Kamble. Synthesis and anti-inflammatory and antimicrobial activities of some novel 2-methylquinazolin-4(3H)-one derivatives bearing urea, thiourea and sulphonamide functionalities. Arab. J. Chem. 2019; 12, 1522-31.

[5] ASD Oliveira, LFSD Souza and RJ Nunes. Antioxidant and antibacterial activity of sulfonamides derived from carvacrol: A structure-activity relationship study. Curr. Top. Med. Chem. 2019; 20, 173-81.

[6] FG Young. Hypoglycaemic and antidiabetic suiphonamides. Br. Med. J. 1956; 2, 431-2.

[7] Y Kwon, J Song, H Lee, EY Kim, K Lee, SK Lee and S Kim. Design, synthesis, and biological activity of sulfonamide analogues of antofine and cryptopleurine as potent and orally active antitumor agents. $J$. Med. Chem. 2015; 58, 7749-62.

[8] A Kaur, DP Pathak, V Sharma and S Wakode. Synthesis, biological evaluation and docking study of a new series of di-substituted benzoxazole derivatives as selective COX-2 inhibitors and antiinflammatory agents. Bioorg. Med. Chem. 2018; 26, 891-902.

[9] A Kumar and D Kumar. Synthesis and antimicrobial activity of metal complexes from 2-(1'/2'hydroxynaphthyl)benzoxazoles. Arkivoc 2007; 14, 117-25.

[10] J Vinšová, V Horák, V Buchta, J Kaustová. Highly lipophilic benzoxazoles with potential antibacterial activity. Molecules 2005; 10, 783-93.

[11] J Wang and L Hong. Application of nitrile in drug design. Chin. J. Org. Chem. 2012; 32, 1643-52.

[12] A Gomtsyan. Heterocycles in drugs and drug discovery. Chem. Heterocycl. Comp. 2012, 48, 7-10.

[13] TE Odlaug. Antimicrobial activity of halogens. J. Food Prot. 1981; 44, 608-13.

[14] RV Satyendra, KA Vishnumurthy, HM Vagdevi, BL Dhananjaya and A Shruthi. Synthesis, in vitro anthelmintic, and molecular docking studies of novel 5-nitro benzoxazole derivatives. Med. Chem. Res. $2015 ; 24,1342-50$.

[15] G Cholewinski, D Iwaszkiewicz-Grzes, P Trzonkowski and K Dzierzbicka. Synthesis and biological activity of ester derivatives of mycophenolic acid and acridines/acridones as potential immunosuppressive agents. J Enzyme Inhib Med Chem. 2016, 31, 974-982.

[16] S Ahmed, AJ Al-rehaily and P Alam. Antidiabetic, antioxidant, molecular docking and HPTLC analysis of miquelianin isolated from Euphorbia schimperi C. Presl. Saudi Pharm. J. 2019; 27, 65563.

[17] NMO Boyle, M Banck, CA James, C Morley, T Vandermeersch and GR Hutchison. Open babel: An open chemical toolbox. J. Cheminformat. 2011; 3, 33.

[18] W Brand-Williams, ME Cuvelier and C Berset. Use of a free radical method to evaluate antioxidant activity. LWT Food Sci. Tech. 1995; 28, 25-30.

[19] P Prieto, M Pineda and M Aguilar. Spectrophotometric quantitation of antioxidant capacity through the formation of a phosphomolybdenum complex: Specific application to the determination of vitamin E. Anal. Biochem. 1999; 269, 337-41.

[20] M Oyaizu. Studies on products of browning reaction. Antioxidative activities of products of browning reaction prepared from glucosamine. Jpn. J. Nutr. Diet. 1986, 44, 307-15.

[21] J Kim, C Kwon and K ho Son. Inhibiion of alpha-glucosidase and amylase by luteolin, a flavonoid. Biosci. Biotechnol. Biochem. 2000, 64, 2458-61.

[22] Worthington Biochemical Corporation. Amylase alpha - Worthington enzyme manual, Available at: http://www.worthington-biochem.com/AA, accessed January 2021.

[23] IG Tamil, B Dineshkumar, M Nandhakumar, M Senthilkumar and A Mitra. In vitro study on amylase inhibitory activity of an Indian medicinal plant, Phyllanthus amarus. Indian J. Pharmacol. $2010 ;$ 42, 280-2. 